\title{
0 conceito de técnica no futebol: um ensaio sobre perspectivas restritivas e de ampliação
}

\author{
The technique concept in soccer: an essay on restrictive \\ and magnification perspectives
}

Cesar Vieira Marques Filho', Antonio Guilherme Schmitz Filho', Eurico Barcelos dos Santos', Heitor dos Santos Daronch', Otávio Baggiotto Bettega²

Universidade Federal de Santa Maria (UFSM), Santa Maria, RS, Brasil.

¿Universidade Federal de Santa Catarina (UFSC), Florianópolis, SC, Brasil.

Recebido em: 31/03/2015 / Aceito em: 25/04/2016

cesarvmf@hotmail.com

\section{RESUMO}

A técnica é um elemento cuja importância ganha grande relevância nas publicações que dizem respeito ao futebol, mesmo que sua conceituação não tenha uma definição exata e unânime para os diferentes autores. Este trabalho busca verificar as discrepantes perspectivas de atribuições desenvolvidas para o conceito de técnica nos diferentes segmentos que trabalham com futebol. Com base em uma revisão de literatura surgem ponderações que perspectivam reconhecer restrições e ampliações de uma conceituação ou desenvolvimento de uma noção para a técnica, partindo de alguns pontos de análise, envolvendo a própria restrição e a ampliação de novas compreensões para o conceito.

Palavras-chave: Futebol; Destreza Motora; Teoria do Jogo.

\section{ABSTRACT}

Technique is an element whose importance gains great relevance in publications related to soccer, even though its conceptualization not has an accurate and unanimous definition for different authors. This job aims verify the differing perspectives assignments developed for the technique concept in different segments that works with soccer. Based on a literature review considerations arise which envisage recognize restrictions and magnifications of a conceptualization or developing a concept for technique from some points of analysis, involving the restrictions themselves and expansion of new understandings about this concept.

Keywords: Soccer; Motor Skill; Game Theory.

\section{INTRODUÇÃO}

A utilização do termo "técnica" é muito corriqueira, quando se fala em futebol. Ela é comumente associada à capacidade que jogadores têm de realizar movimentos com ou sem a bola durante as partidas. Um passe de alta precisão, um cabecear certeiro e um chute eficiente de longa distância, são exemplos de ações que ocorrem dentro do jogo e que demonstra relevância na qualidade técnica dos jogadores que as executam. Nesse sentido, a técnica caracteriza-se como um sistema específico de ações simultâneas, das quais operam como consequência da intenção de forças externas e internas com o objetivo de alcançar uma maior eficácia. ${ }^{1-3}$

A extraordinária habilidade de alguns jogadores brasileiros os identificou como personagens tecnicamente privilegiados. Didi apresentou ao mundo do futebol a chamada "folha-seca", maneira peculiar e precisa com que cobrava faltas, onde a trajetória da bola mudava de repente, surpreendendo os goleiros. Muitos creditam à capacidade única de finalização de Pelé, com ambos os pés e a cabeça, o fato de ter atingido a marca de mais de mil gols marcados. Leal ${ }^{4}$ aponta nomes famosos na arte de cabecear: Baltazar, o "cabecinha de ouro", Leivinha, Dionísio, Jardel e Dadá Maravilha (que pairava no ar tal qual o beija-flor e o helicóptero).

Nesse contexto, no qual os jogadores caracterizam-se pelas suas peculiaridades técnicas, a observação, quando voltada ao jogo, deve interligar fatores técnicos à esfera tática do jogo. ${ }^{5-7}$ O futebol, assim como os demais esportes, passou por algumas alterações, principalmente com referência aos aspectos estruturais e normativos, que influenciaram diretamente 
nos componentes técnico-táticos do jogo. Os sistemas táticos e as incumbências atribuídas aos atletas foram se modificando e adaptando aos novos modelos de jogo. Parreira ${ }^{8}$ aponta que nas planificações táticas mais antigas, a distribuição dos jogadores era configurada com maior priorização para o setor ofensivo.

Em contrapartida, essa relação organizacional dos jogadores atribuída aos setores de defesa e ataque foi configurando-se com maior equilíbrio. Garganta7 ratifica que as estratégias voltaram-se também para os aspectos defensivos, alterando as condições táticas do jogo e consequentemente as representações técnicas dos jogadores. Nesse sentido, mesmo enfocando-se a técnica como tema base desse estudo, salienta-se que tais conceitos (estratégia - tática - técnica) são indissociáveis.

A compreensão da técnica, em muitas situações, é desvinculada do seu contexto, ganhando diferentes entendimentos e proposições. Essas atribuições ao conceito de técnica podem ser percebidas no senso comum ou até mesmo nas plataformas especializadas em cenários esportivos e, principalmente, nos casos que envolvem o futebol. A técnica visualizada no sentido exterior e treinada com o intuito da modelação corporal aloca-se na representação do gesto, não intencionando a compreensão dos significados despertados no indivíduo e no contexto. ${ }^{9}$

Para tanto, as diversas conceituações atribuídas à técnica são desencadeadas a partir de diferentes percepções, que operam sustentadas nos seus objetivos e experiências. Nessa relevância, o estudo de cunho bibliográfico do tipo descritivo-reflexivo intenciona verificar as diferentes atribuições desenvolvidas para a técnica, considerando para tanto, perspectivas restritivas e de ampliação, estabelecidas para a sua conceituação ou para o desenvolvimento de uma noção de técnica, tomadas como referência, junto aos diversos níveis ou segmentos que trabalham com futebol.

\section{MÉTODO}

A metodologia empregada com base em pesquisas bibliográficas busca suporte no aspecto temporal que envolve determinada discussão em campo de conhecimento específico. Neste sentido, as características históricas e os apontamentos críticos de determinada época adquirem importância e constroem o protagonismo para um novo patamar científico de debate. Ao se revisar o status de um saber específico, cria-se a oportunidade de analisar com mais profundidade aquilo que foi cuidadosamente desenvolvido por outros pesquisadores. Ressalta- se que a pesquisa bibliográfica implica em um conjunto ordenado de procedimentos de busca por soluções, atento ao objeto de estudo, e que, por isso, não pode ser aleatório. ${ }^{10}$

O diálogo conferido com o arcabouço bibliográfico transcende pelo percurso histórico, partindo de estudos pioneiros no âmbito esportivo, ${ }^{11-13}$ estudos categóricos nessa temática ${ }^{2,3,14,15}$ e pesquisas mais específicas da modalidade de futebol. ${ }^{5,7}$ A busca ocorreu com base em livros, trabalhos acadêmicos, artigos e outros materiais científicos e debruçou-se a partir de perspectivas restritivas e de ampliação vinculadas à conceituação, com vistas ao desenvolvimento de uma noção de técnica.

\section{RESULTADOS E DISCUSSÃO}

\section{Perspectivas restritivas para o conceito de técnica}

Existem muitas produções literárias que abordam o tema da técnica no futebol. Frequentemente apresentam uma conceituação bastante pontual sobre ela, com uma definição que a limita na esfera gestual. Esse tipo de concepção considera apenas a forma com que um atleta realiza um movimento e, por muitas vezes, impõe uma maneira ou modelo correto de se realizar esse movimento. Esse pensamento fragmentado, que não leva em consideração todas as relações existentes em um jogo de futebol, apresenta um entendimento para uma noção de técnica de forma restrita.

Segundo Mutti, ${ }^{16}$ a técnica consiste na execução individual dos fundamentos básicos do futebol; isto é, do passe, do chute, da recepção de bola, do drible e etc; no caso do goleiro consiste na pegada, lançamento, espalmada, entre outras. Dellal et al. ${ }^{17}$ expõe que a técnica é comporta as ações dos chutes, passes, mecanismos para manter a posse de bola e para recuperá-la. Filguei$\mathrm{ra}^{18}$ aponta a técnica como uma ação motora perfeita que proporciona o maior nível de desempenho no atleta, da forma mais objetiva e econômica possível. Segundo o mesmo autor, a técnica é comum a todos os atletas e formada pelos fundamentos do esporte.

Leal ${ }^{4}$ dispõe a técnica como um conjunto de fundamentos básicos que diferencia o futebol dos demais esportes, cuja peculiaridade está, principalmente, no uso dos pés e pernas para executar as ações básicas para defender (desarmar), manter a bola (dominar, controlar, levantar, proteger, conduzir e passar), para marcar gols. Na conceituação de Mahlo, ${ }^{11}$ a técnica é a execução dos elementos fundamentais do jogo, isto é, de todas as habilidades que o praticante necessita para se tornar um jogador de futebol. É a execução do chute, passe, drible, finta, cabeçada; é a travada da bola nas mais variadas maneiras; é a "tirada", o uso do tranco, a cabeçada; é a habilidade de proteger a bola com o corpo; é a perfeita execução do "tiro de canto", "tiro de penalidade máxima", "tiros livres", "arremessos laterais", "tiros de meta"; é, por fim, a habilidade de jogar no gol.

O sentido dado a essas abordagens restringe a técnica ao simplificá-la, como sendo apenas lances que o jogador realiza durante o jogo. Essa visualização ocorre em uma perspectiva individual, centralizando no gesto do atleta e não nas suas relações com o coletivo. Preconizando-a com uma ação motora, dá-se a entender que ela se ligada apenas à maneira com que cada atleta realiza determinador fundamento do futebol. Não há o pensamento de que um gesto que pode não ser considerado ideal ou com menor eficiência pode vir a ser a solução para uma situação imposta no jogo.

Santos Filho ${ }^{19}$ diz que o conceito trata-se da forma racional, ideal e eficiente de executar os movimentos na pratica do futebol, com uma economia de esforço e energia. Seus princípios podem ser assimilados com o treinamento e a prática constante. Esta ideia representa a técnica como uma forma mais simples e menos desgastante de realizar movimentos. Expõe que com 
a prática em treinamento, o aprimoramento gera uma menor demanda física necessária para a realização das ações. Alguns artigos internacionais ligados a critérios fisiológicos e biomecânicos corroboram com esta abordagem. ${ }^{20-22}$

Segundo Graciano, ${ }^{23}$ o jogador que possuir maior capacidade técnica com a bola, em qualquer situação do jogo conseguirá maior êxito para a sua equipe. A equipe que possuir maior número de jogadores técnicos e mais esforço físico obterá sempre maior vantagem contra equipes consideradas inferiores. Nesta apresentação, credita-se à técnica, a exclusividade sobre o sucesso de um jogador/equipe, não abrangendo demais fatores do jogo como organização defensiva e ofensiva, posicionamento e entrosamento. Também se percebe a crença em que o domínio das capacidades técnicas é o suficiente para que o praticante se torne um qualificado jogador de futebol.

Observa-se que a necessidade do isolamento da técnica em uma questão de execução do movimento restringe ou impede o estabelecimento de uma relação mais elaborada com o contexto tático do jogo que a envolve. Este sentido, direcionado ao individual, sem relações elementares de contexto, reforça alguns aspectos restritivos que agregam ao conceito pontos de vista únicos ou localizados em uma ação isolada.

Também cabe ponderar que a discussão de técnica é dependente das relações estabelecidas entre o atacar e o defender. Por vezes, a técnica representada nos fundamentos do jogo, implica naquilo que ocorre no enfrentamento estabelecido entre as equipes e não somente naquilo que se estima como o correto para a situação. A técnica é dependente do momento e como tal deve ser interpretada entre uma ou várias possibilidades. Se houver uma possibilidade apenas de interpretação para a técnica, os aspectos restritivos serão preponderantes e de certa forma reforçarão a fragmentação do conceito.

O quadro 1 traz as perspectivas restritivas e de ampliação para o conceito de técnica alicerçadas por premissas referentes ao pensamento cartesiano e ao pensamento sistêmico. Isso posto, ressalta-se que as perspectivas restritivas compreendem a técnica a partir do pensamento cartesiano, em que soma das partes, formam o todo. Todavia, as perspectivas de ampliação entendem a técnica com base no pensamento sistêmico, em que a interação das partes forma o todo. ${ }^{14,24}$

A mudança de pensamento, da visão cartesiana para visão sistêmica, permeou por várias questões conceituais e de entendimento, como demonstrado no quadro acima. Tais elementos serão abordados no próximo item.

\section{Perspectivas de ampliação do conceito de técnica}

Também existem na literatura apreciações mais abertas e ampliadas para a noção de técnica. A ligação dela com outros fatores, tais como a função ocupada pelo jogador dentro de campo, o setor de atuação no jogo, a situação posta em relação à equipe adversária e suas características físicas, possibilitam transcender a esfera de um entendimento individualizado e fragmentado para o conceito.

$\mathrm{Braz}^{25}$ aponta que são importantes fatores de performance, a resistência e padrão de demonstração de técnica em regime de fadiga, em contexto que imprime também níveis consideráveis de tensão psicológica, pela precisão técnica exigida na execução de movimentos que, em algumas situações, são evidenciados pela procura de correções em sua execução, quando julgada inadequada. $\mathrm{O}$ mesmo autor apresenta novas variáveis a serem consideradas quando se fala em avaliar a técnica de um atleta. Seu nível de cansaço, bem como a forma com que reage a certas pressões de cunho psicológico, podem influenciar diretamente na realização técnica dos lances no jogo.

Bayer $^{13}$ ratifica que a coordenação motora tem grande importância para o domínio técnico e para a aprendizagem motora. Capacita um desportista a dominar movimentos complicados e a aprender movimentos novos no menor tempo. Possibilitam um poder de adaptação, de orientação, de percepção espacial, de percepção de tempo, de movimentos, capacidades de transferir movimentos, poder de equilíbrio, precisão e ritmo. Ligada a uma série de elementos, os autores realçam a importância da coordenação motora na capacidade técnica dos atletas, relacionando-a com aspectos como percepção espacial e de tempo, aspectos estes que tem ligação direta com a relação do atleta com o contexto do jogo. ${ }^{26-29}$

Outros entendimentos contrapõem o ideal de que a boa técnica está ligada a uma execução correta de um gesto, pois o gesto é apenas utilizado para realizar uma ação dentro de uma situação de jogo. ${ }^{30-32}$ Mesquita $^{33}$ salienta que jogo é constituído por componentes técnicos e táticos, sendo que a técnica está embutida na constituição da tática. Na situação de jogo, um passe realizado por um jogador não pode ser analisado somente pela sua técnica de execução. Esse ato altera o andamento do jogo, condicionando a movimentação individual e coletiva das equipes e consequentemente interferindo na tática do jogo. A técnica não tem nenhum sentido sem a tática, porém esta não poderá cumprir seus objetivos sem a ajuda da técnica. ${ }^{34}$ Neste contexto, um passe errado pode não ser caracterizado por um movimento ruim, mas sim por uma má escolha

Quadro 1 - Caracterização das perspectivas restritivas e de ampliação para o conceito de técnica.

\begin{tabular}{|c|c|}
\hline PERSPECTIVAS RESTRITIVAS & PERSPECTIVAS DE AMPLIAÇÃO \\
\hline Pensamento Cartesiano & Pensamento Sistêmico \\
\hline $\begin{array}{c}\text { Entendimento do todo com base na redução } \\
\text { e fragmentação das partes. }\end{array}$ & $\begin{array}{c}\text { Visão do todo integrado cujas propriedades não podem } \\
\text { ser reduzidas as de partes menores. }\end{array}$ \\
\hline O todo visto como uma coleção de objetos fragmentados. & Objetos vistos como redes de relações encaixadas em redes maiores. \\
\hline O desenvolvimento da técnica desvinculado do contexto tático do jogo. & O desenvolvimento da técnica contextualizado com as condições táticas do jogo. \\
\hline
\end{tabular}


da opção de passe ou por mérito do adversário de antever o lance e conseguir interceptar a bola.

Tais elementos apresentam condições influenciadoras para o sucesso ou insucesso do atleta no lance que vão além da simples realização correta do gesto. Para Campello et al., ${ }^{35}$ um bom executante é, alguém capaz de selecionar as habilidades técnicas mais adequadas para dar resposta às sucessivas configurações do jogo. Segundo Garganta, ${ }^{36}$ a verdadeira dimensão da técnica repousa na sua utilidade para servir a inteligência e a capacidade de decisão tática dos jogadores e das equipes. A técnica está ligada a uma decisão tática previamente estabelecida, deste modo, técnica e tática se condicionam reciprocamente formando uma unidade de ação. ${ }^{37}$

Daolio $^{38}$ afirma que jogar bem não seria apenas executar de forma eficiente um conjunto de técnicas, mas, além disso, contribuir de forma cooperativa e inteligente para o sucesso do empreendimento coletivo. Dentro da complexidade das relações do jogo, as tomadas de decisões vão influenciar diretamente a execução dos movimentos. Um jogador que marca muitos gols de cabeça, pode não ter na técnica da cabeçada sua grande qualidade. A formatação da equipe pode levar a que ele tenha inúmeras situações de finalização de bolas aéreas, bem como seu posicionamento pode ser um diferencial para levar vantagem no lance.

Ao rever algumas indicações de abrangência para o conceito da técnica, percebe-se a associação do conceito com a uma ou mais intenções táticas. Tal pressuposição caracteriza a complexidade que envolve um entendimento mais apurado para o conceito. A técnica é interdependente da tática; assim como a tática também é interdependente da técnica. Para tanto, em situações que priorizam a análise do conceito, a inter-relação estabelecida entra elas (técnica e tática) deverá ser uma constante observada e considerada no processo de discussão.

Outro ponto importante de consideração é a utilização do termo "técnico-tático" que, por si só, reforça o contexto relacional entre os conceitos e a sua composição como elemento articulador para a solução de problemas durante o jogo. Técnica e tática surgem como complementares e se sobrepõem o tempo todo durante as discussões sobre a dinâmica estabelecida nos diversos enfrentamentos que ocorrem durante uma partida. Uma tomada de decisão ou a opção de realizar uma ação em detrimento de outra(s), refere-se ao emprego da técnica e a estreita ligação desta com a situação tática posta.

O francês Pierre Parlebas, ${ }^{39}$ em sua teoria denominada Praxiologia Motriz, agrega os elementos técnico-táticos para sua discussão no contexto do jogo sob o conceito de Ação Motriz. Assim, corroborando com a compreensão de que técnica e da tática são indissociáveis, a Ação Motriz é amplamente utilizada por pesquisadores da Praxiologia Motriz ao tratar de futebol, tendo as produções mais relevantes advindas da Espanha. ${ }^{40-42}$

\section{CONSIDERAÇÕES FINAIS}

Nas apreciações realizadas pelos vários segmen- tos que trabalham com futebol, é quase unânime a ideia de que a técnica seja um dos principais elementos de domínio necessário para um jogador. Muitos condicionam o bom desempenho desses atletas a estarem tecnicamente bem qualificados. Porém, esse aspecto crucial é abordado de algumas maneiras não condizentes com a sua importância; muitas vezes é resumido em simples lances do jogo como passar, chutar, cabecear. Não é especificado como ocorrem esses momentos dentro do contexto do jogo e de que forma o atleta participa deles para ter ou não êxito. Abordagens reduzidas parecem não colaborar para a formação de uma compreensão mais adequada ou aprofundada daquilo que a técnica trata ou a caracteriza. São encontrados fatores limitantes nessas formas de compreender a técnica.

Existe também uma série de produções que conotam uma visão mais aberta para a definição de uma noção de técnica, relacionando-a sempre com todo ambiente do jogo que a cerca. A capacidade cognitiva do jogador é citada e o êxito em uma ação está muitas vezes mais ligado a sua tomada de decisão do que na forma com que ele realizou o movimento. É possível se entender que uma qualidade elevada na realização dos gestos motores será muito importante para um jogador, porém, isso não pode ser visto como a definição de sua capacidade técnica, mas sim como uma forma do mesmo ter autonomia para melhor encontrar soluções às situações apresentadas durante o jogo.

A formação de um pensamento abrangente, que considera todas essas variáveis, contrapõe ideias restritivas de técnica e colabora na formação de um entendimento mais autônomo para o conceito. Desta forma, a revisão colabora para a melhoria da compreensão do conceito/noção de técnica e como tal melhoria pode se articular em um contexto efetivamente prático. Possibilita ingressar em partes específicas de discussão para o ensino esportivo ou o treinamento de futebol, estabelecendo algumas pressuposições a partir da revisão (ou daquilo que a revisão apresentou) com uma concepção ou ideia de relação com o conceito ou a noção de tática.

\section{REFERÊNCIAS}

1. Hegedus J. La Ciencia de Entrenamiento Deportivo. Buenos Aires: Stadium, 1984.

2. Riera J. Estrategia Táctica y Técnica Deportivas. Apunts. Educación Física y Deportes. Barcelona 1995;39:45-56.

3. Weineck JM. Treinamento Ideal. Barueri: Manole, 1999.

4. Leal JC. Futebol - Arte e Ofício. Petrópolis: Sprint, 1999.

5. Garganta J, Pinto JMR. O Ensino do Futebol. In: Graça A; Oliveira AJ. (Orgs.). O ensino dos jogos desportivos: Coimbra: FCDEF-UP. 1994; p.97-137.

6. Pinto JMR. Administração e liberdade: Um estudo do conselho de escola a luz da teoria da ação comunicativa de Jurgen Habermas. 1984. 191 f. Tese (Doutorado em Educação) - Faculdade de Educação, Universidade Estadual de Campinas, Campinas. 1994.

7. Garganta J. Modelação Táctica do Jogo de Futebol: Estudo da Organização da Fase Ofensiva em Equipas de Alto Rendimento. 1997. 318 f. Tese (Doutorado em Educação Física) - Faculdade de Ciências do Desporto e da Educação Física, Universidade do Porto, Porto. 1997.

8. Parreira, CA. Evolução Tática e Estratégias de Jogo. Brasília: 
EBF. 2005.

9. Cunha e Silva P. O Lugar do Corpo. Elementos Para uma Cartografia Fractal. 1995. 311 f. Tese (Doutorado em Ciência do Desporto) - Faculdade de Ciências do Desporto e da Educação Física, Universidade do Porto, Porto. 1995.

10. Lima TCS, Mioto RCT. Procedimentos metodológicos na construção do conhecimento científico: a pesquisa bibliográfica. Rev Katalysis 2007;10:35-45. DOI: 10.1590/ S1414-49802007000300004.

11. Mahlo F. O Acto Táctico no Jogo. Lisboa: Compedium. 1969.

12. Teodorescu L. Théorie et Méthodologie des Jeux Sportifs. Paris: Les Editeurs Français Réunis. 1977.

13. Bayer C. L'Enseignement des Jeux Sportifs Collectifs. Paris: Vigot. 1979.

14. Garganta J. Para uma teoria dos jogos desportivos colectivos. In: Graça A, Oliveira AJ. (Org.). O ensino dos jogos desportivos. $2^{\mathrm{a}}$ ed. Faculdade de Ciências do Desporto e da Educação Física, Universidade do Porto. 1994.

15. Moreno H. Fundamentos del Deporte: Análisis de la Estructura del Juego Deportivo. Barcelona: INDE, 1994.

16. Mutti D. Futsal: Da Iniciação ao Alto Nível. São Paulo: Phorte. 2003.

17. Dellal A, Wong DP, Moalla W, Chamari K. Physical and Technical Activity of Soccer Players in the French Fisrt League: With Special Reference to Their Playing Position. International SportMed Journal for Fims 2010;11(2):278-90.

18. Filgueira FM. Aspectos físicos, técnicos e táticos da iniciação ao futebol. Rev Digital, Buenos Aires. 2006;11(103):1. Disponível em: <http://www.efdeportes.com/efd103/ iniciaciao-futebol.htm>. Acesso em: 20 de Dez. 2013.

19. Santos Filho JL. A. Manual do Futebol. São Paulo: Phorte, 2002.

20. Rampinini E, Impellizzeri FM, Castagna C, Coutts AJ, Wisloffe U. Technical Performance During Soccer Matches of the Italian Serie A league: Effect of Fatigue and Competitive Level. Journal of Science and Medicine in Sport 2009;12(1):227-33. DOI: 10.1016/j.jsams.2007.10.002.

21. Kelly DM, Drust B. The Effect of Pitch Dimensions on Heart Rate Responses and Technical Demands of SmallSided Soccer Games in Elite Players. Journal of Science and Medicine in Sport 2009;12(4):475-9. DOI: 10.1016/j. jsams.2008.01.010

22. Tessitore A, Meeusen R, Piacentini MF, Demarie S, Caprinica L. Physiological and Technical Aspects of "6-a-side" Soccer Drills. Journal of Sports Medicine and Physical Fitness 2006;46(1):36-43.

23. Graciano V. A Arte e a Técnica do Futebol. São Paulo: Roswhita Kempf, 1984.

24. Capra F, Luisi PL. A visão sistêmica da vida: uma concepção unificada e suas implicações filosóficas, políticas, sociais e econômicas. São Paulo: Editora Cultrix, 2014.

25. Braz TV. Análise de jogo no futebol: Considerações sobre o componente técnico-tático, planos de investigação, estudos da temática e particularidades do controle das ações competitivas. Ver Bras de Futsal e Futebol, São Paulo 2013;5(15):28-43.

26. Freire JB. Pedagogia do Futebol. Campinas: Autores Associados, 2006.

27. Gallahue DL. A Classificação das habilidades de movimento: Um caso para modelos multidimensionais. Ver da Educ
Fís/UEM, Maringá 2002;13(2):105-11. DOI: 10.4025/ reveducfisv13n2p105-111

28. Passos P, Lopes R, Milho J. Análise de Padrões de Coordenação Interpessoal no Um-Contra-Um no Futebol. Ver. Port. de Ciênc. do Desp., Porto. 2008;8(3):365-76.

29. Portal MND, Silva JB, Saraiva A, Monte Junior GC, Chaves LGS, Amaral Neto AM, Silva AJ, Dantas EHM. Avaliação dos Efeitos do Treinamento em Crianças Futebolistas da Vila Olímpica da Mangueira. Motricidade, Santa Maria da Feira 2008;4(2):47-53. DOI: 10.6063/motricidade.4(2).510

30. Gréhaigne JF, Godbout P. Tactical Knowledge in Team Sports From a Constructivist and Cognitivist Perspective. National Association for Physical Education in Higher Education 1995;47(4):490-505. DOI: 10.1080/00336297.1995.10484171

31. Hastie PA, Sinelnikv OA, Guarino AJ. The Development of Skill and Tactical Competencies During a Season of Badminton. European Journal os Sport Science. 2009;9(3):133-140. DOI: http://dx.doi.org/10.1080/17461390802542564

32. Kannekens R, Elferink-Gemser MT, Visscher C. Tactical Skills of World-Class Youth Soccer Teams. Journal of Sports Sciences 2009;27(8):807-812. DOI: 10.1080/02640410902894339

33. Mesquita I. Perspectiva Construtivista da Aprendizagem no Ensino do Jogo. In: Nascimento JV, Ramos V, Tavares F. (org.) Jogos Desportivos: Formação e Investigação. Florianópolis: UDESC, 2013. p.103-133.

34. Haro GV, Ortega JP, Cerezo CR, Contreras MIM. Propuesta de Valoración Técnico-Táctica Mediante una Situación de Juego Colectivo Básico en el Fútbol de Iniciación. Retos. Nuevas Tendencias en Educación Física, Deporte y Recreación 2007;(12):29-35.

35. Campello AS, Cendón BV, Kremer JM. Fontes de Informação para Pesquisadores e Profissionais. Belo Horizonte: UFMG, 2000, p. 191-99.

36. Garganta J. Conocimiento y Acción en el Fútbol. Tender un Puente Entre la Táctica y la Técnica. Rev de Entrenam Deport. La Corunã 2001;15(1):15-24.

37. Suarez AA, Casal C, Sanjurjo AC. Metodología de la Enseñanza del Fútbol. Barcelona: Paidotribo, 1 ed., 2007.

38. Daolio J. Jogos Esportivos Coletivos: dos Princípios Operacionais aos Gestos Técnicos - Modelo Pendular a Partir das Idéias de Claude Bayer. Rev Bras Ciênc e Mov, Brasília 2002;10(4):99-104.

39. Parlebas P. Jeux, Sports et Sociétés: Lexique de Praxéolgie Motrice. Paris: Institut du Sport et de L'éducation Physique. 1999.

40. Moreno JH. La Iniciación a los Deportes desde su Estructura y Dinámica: Aplicación a la Educación Física Escolar y al Entrenamiento Deportivo. Barcelona: Inde. 2000.

41. Díaz RD. Análisis Praxiológia de la Dinámica de Juego em Fútbol: Lógica Externa y Lógica Interna. 2015. 437 f. Tese (Doutorado em Praxiologia Motriz, Educação Física e Treinamento Desportivo) - Departamento de Educación Física, Universidad de Las Palmas de Gran Canaria, Las Palmas de Gran Canaria. 2015.

42. TorresCA.LaPraxiologíaenelFútbol:IncidenciasReglamentarias, Acciones Motrices, El Remate y el Gol. EFDeportes.com, Revista Digital. Buenos Aires 2003;18(179). Disponível em: <http:// www.efdeportes.com/efd179/la-praxiologia-en-el-futbol.htm> Acesso em: 12 de mar. 2016 